\title{
Sirtuin 1 ve Sirtuin 2'nin Tip 2 Diyabet ile İlişkisi
}

\author{
İlke ULU ๑, Güneş GENÇ ÇAKMAK ๑, Sevim KARAKAŞ ÇELİK ๑ 凶 \\ Zonguldak Bülent Ecevit Üniversitesi, Tip Fakültesi, Tibbi Genetik Anabilim Dalı. Zonguldak, Türkiye
}

Bu makaleye yapılacak atıf: Ulu İ, Genç Çakmak G, Karakaş Çelik S. Sirtuin 1 ve Sirtuin 2'nin Tip 2 Diyabet ile İlişkisi. Turk J Diab Obes 2021;1: 81-88.

\begin{abstract}
ÖZ
Diabetes mellitus, bütün dünyada ve bütün yaş gruplarında en sık görülen endokrin hastalıktır. Tip 2 diyabet; diyabet vakalarının yaklaşık \%80-90’nı oluşturan ve tipik olarak ileri yaşlarda ortaya çıkan bir hastalıktır. Tip 2 diyabet patogenezi oldukça karmaşıktır ve birçok yönden hâlen tartışma konusudur. Kalıtım poligeniktir ve çevresel faktörlerle güçlü bir ilişkisi mevcuttur. Bozulmuş insulin sekresyonu ve bozulmuş insulin sensitivitesi söz konusudur. Sirtuin ailesi (SIRT) NAD+ bağımlı deasetilazlar olup memelilerde, maya ve yüksek organizmalarda histon deasitalasyonu ve DNA stabilizasyonunu sağlar. Yapılan çalışmalarda onkogenez, uzun ömür, metabolik regülasyon ve nörodejeneratif hastalıklar ile ilişkili olduğu gösterilmiştir. Hücre döngüsünün düzenlenmesi, apoptoz, mitokondriyal biyogenez, lipid metabolizması, yağ asidi oksidasyonu, hücresel stres yanıtı, insülin salgılanması, yaşlanma ve inflamasyon gibi pek çok fizyolojik süreçte rol oynayan sirtuinlerin son yillarda diyabet patogenezinde de oldukça önemli rolü olduğu tespit edilmiştir.
\end{abstract}

Anahtar Sözcükler: Sirtuin, SIRT1, SIRT2, Tip 2 Diabetes mellitus

\section{Relationship Between Sirtuin 1 and Sirtuin 2 with Type 2 Diabetes}

\begin{abstract}
Diabetes mellitus is the most common endocrine disease in the world and in all age groups. Type 2 diabetes is a disease that constitutes approximately $80-90 \%$ of diabetes cases and typically occurs in advanced ages. The pathogenesis of type 2 diabetes is quite complex and is still a matter of debate in many aspects. Heredity is polygenic and has a strong relationship with environmental factors. There is impaired insulin secretion and impaired insulin sensitivity. The Sirtuin family (SIRT) members are NAD+ dependent deacetylases that provide histone deacetylation and DNA stabilization in mammals, yeast and higher organisms. Studies have shown that it is associated with oncogenesis, longevity, metabolic regulation and neurodegenerative diseases. Sirtuins, which play a role in many physiological processes such as cell cycle regulation, apoptosis, mitochondrial biogenesis, lipid metabolism, fatty acid oxidation, cellular stress response, insulin secretion, aging, and inflammation, have been found to have a significant role in diabetes pathogenesis in recent years.
\end{abstract}

Keywords: Sirtuin, SIRT1, SIRT2, Type 2 Diabetes mellitus,

ORCID: İlke ULU / 0000-0001-8695-5833, Güneş GENÇ ÇAKMAK / 0000-0001-7222-0377, Sevim KARAKAŞ ÇELİK / 0000-0003-0505-7850 


\section{GİRIŞ}

Tip 2 diabetes mellitus, insülin direnci ve $\beta$ hücrelerinden insülin salınımındaki defektler sonucu bozulmuş lipid ve glikoz metabolizması nedeniyle görülen hiperglisemi ve dislipidemi ile karakterize bir hastalıktır (1). Günümüzde tüm dünyada tip 2 diyabet hastası bireylerin sayısı giderek artmaktadır. Ülkemizde de hastalık prevelansının yaklaşık $\% 13,7$ olduğu gösterilmiştir (2). Obezite ve sedanter yaşam tarzı tip 2 diyabet insidansının artmasına neden olan başl1ca risk faktörlerindendir $(3,4)$. Genetik yatkınlık ve etnik köken ile birlikte dengesiz beslenme, fiziksel inaktivite, ileri yaş, yüksek kan basınc1, bozulmuş glikoz toleransı ve gestasyonel diyabet öyküsü tip 2 diyabet gelişimi ile ilişkili diğer risk faktörleridir (5). Dünyayı ve ülkemizi etkileyen ve önlenebilir olan tip 2 diyabetin sürdürülebilir hedefler ile durdurulması gerekmektedir. Yaşam tarzı müdahaleleri metabolik kontrol için oldukça önemlidir ve tip 2 diyabet yönetiminde ilk sırada yer almaktadır (6). Alınan enerjinin kısitlanması ve/veya harcanan enerjinin artırılması ile adipoz doku azaltılıp kilo kontrolü sağlanarak insülin aktivitesi ve glikoz toleransı artar (7). Beslenme şekli değişiklikleri ile tip 2 diyabet semptomlarının iyileştirilerek tedavi ihtiyac1nın azaltılabildiği gösterilmiştir (8).

Sirtuinler (SIRT) nikotinamid adenin dinükleotid (NAD +) bağımlı tip III histon deasetilazlardır. Histon deasetilazlar (HDAC) spesifik histon ve non-histon proteinlerin deasetilasyonunu sağlayan önemli epigenetik düzenleyicilerdir (9). İlk kez Klar ve ark. tarafından mayada (saccharomyces cerevisiae) ömrü uzattığı gösterilen Sir2 (Silent Information Regulatory 2), sirtuin ailesinde keşfedilen ilk gendir (10).

İnsanda Sirtuin ailesinin farklı hücresel bölmelerde lokalize olan ve çeşitli etkilere sahip yedi üyesi (SIRT 1-7) bulunmaktadır (10). Tüm sirtuinler yaklaşık 200-275 amino asitlik korunmuş katalitik çekirdek alan ve özgün olarak değişen uzunlukta ilave $\mathrm{N}$-terminal ve/veya C-terminal diziler içermektedir (11). Sirtuin üyelerinin hücrede primer lokalizasyonu, bu proteinlerin önemli ölçüde değişen fonksiyonel ayrımını yansitır (12). SIRT1, SIRT6 ve SIRT7, histonları deasetile eder ve gen ekspresyonunu epigenetik olarak etkiledikleri nükleusta lokalize olur. SIRT1 ayrıca, sitoplazmada spesifik transkripsiyon faktörlerini ve enzimleri de deasetile eder. SIRT2 ilk başta sitosolik sirtuin olarak tanımlanmıştır, ancak son veriler SIRT2'nin hücre döngüsü kontrolünü modüle ettiğini ve nükleusta da bulunduğunu göstermektedir. SIRT3, SIRT4 ve SIRT5 mitokondride lokalizedir ve genel olarak mitokondriyal oksidatif metabolizmayı artırarak kalori kisitlamasına cevap vermektedirler (13).

Sirtuin ailesinin etki ettiği en önemli mekanizmaların başında gen ifadesinin düzenlenmesi gelir. Histonların dease- tilasyonu kromatinin yoğunlaşmasını (heterokromatin) ve böylece de gen ifadesinin baskılanmasını sağlar (14). Ayrıca çeşitli transkripsiyon faktörlerinin ve enzimlerin deasetilasyonu ile birçok hücresel mekanizmayı düzenler. En güçlü deasetilasyon aktivitesini SIRT1 gösterirken, SIRT5 zayıf deasetilasyon aktivitesi gösterir (10). Hücre döngüsünün düzenlenmesi, apoptoz, mitokondriyal biyogenez, lipid metabolizması, yağ asidi oksidasyonu, hücresel stres yanıtı, insülin salgılanması, yaşlanma ve inflamasyon gibi pek çok fizyolojik süreçte rol oynayan sirtuinler; kanser, diyabet, karaciğer yağlanması, yaşlanmaya bağlı hastalıklar ve nörodejeneratif hastalıklar gibi pek çok hastalıkla ilişkilendirilmiştir $(9,14,15)$.

Son yıllarda sirtuinler ile glikoz hemostazı ve insülin sekresyonu arasında ilişkiyi gösteren bilgiler bu proteinlerin insülin direnci ve diyabet oluşumunda etkili olabileceğini göstermektedir. SIRT1 ve SIRT2'nin diyabet ile ilişkisini araştıran literatür bilgileri aşağıda derlenmiştir.

\section{Sirtuin 1 (SIRT1)}

SIRT1, memelilerde maya Sir2 proteinine yüksek benzerlik gösteren ve hakkında en çok çalışma yapılan sirtuindir (16). SIRT1, histon proteinlerinin amino kuyruklarındaki lizin amino asitlerini deasetile ederek gen ifadesinin düzenlenmesinde rol oynar. Histon kuyruklarının bu modifikasyonları, belirli biyolojik işlemlerin altında yatan gen susturma ve heterokromatin oluşumuyla yakından ilgilidir (17).

SIRT1; apoptoz inhibisyonu, mitokondriyal biyogenez, inflamasyonun inhibisyonu, glikoz ve lipit metabolizmasının, sirkadiyen ritmin ve hücresel stres adaptasyonunun düzenlenmesinde etkindir (18). Ayrıca SIRT1, besin yoksunluğunda rRNA transkripsiyonunu azaltır, böylece enerji tüketimini azaltarak hücre ömrünü uzatır (19).

SIRT1 aktivasyonu tip 2 diyabet hastalarında glikoz/lipid metabolizmasında önemli bir rol oynar (Şekil 1). Pankreasta, $\beta$ hücrelerini korur ve insülin sekresyonunu artırır. Yağ dokusunda lipid mobilizasyonunu artırır, iskelet kaslarında glikoz alımını artırır ve mitokondriyal biyogenezi indükler (18). Ayrıca, karaciğer ve kaslarda insülin duyarlılığının artmasina neden olur (20). SIRT1, pankreasta UCP2 (uncoupling protein2)'yi baskılayarak $\beta$ hücrelerinden insülin salgılanmasını artırır ve FOXO ile etkileşime girerek bu hücrelerin hayatta kalmasını teşvik eder (21). Ayrıca, Lee ve ark. SIRT1'in, NF- $\kappa B$ sinyalleşmesini baskılayarak $\beta$ hücrelerini oksidatif stres ve sitokinler gibi çeşitli toksik streslere karşı koruduğunu göstermiştir. SIRT1 aşırı ekspresyonu sitokin aracılı sitotoksisiteyi, nitrik oksit üretimini ve nitrik oksit sentaz ekspresyonunu (iNOS) önlemektedir. SIRT1 NF- $\kappa B$ p65 ünitesinin deasetilasyonu yoluyla iNOS ekspresyonunu inhibe etmektedir (22). Başka bir çalışmada 
yine, $\beta$ hücrelerine özgü SIRT1 aşırı eksprese eden (BESTO) transgenik farelerde, pankreatik $\beta$ hücrelerinde $\operatorname{artan}$ SIRT1 seviyelerinin, glukoz toleransını ve glukoza cevaben insülin sekresyonunu artırdığı gösterilmiştir (23). SIRT1, enzimatik aktivitesi için $\mathrm{NAD}^{+}$gerektirdiğinden, yaşla birlikte NAD biyosentezindeki düşüş, SIRT1 aktivitesinde önemli bir azalmaya ve $\beta$ hücrelerinde glukoza duyarlı insülin sekresyonunda düşüşe neden olur. Bununla birlikte, normal $\mathrm{NAD}^{+}$biyosentezinin korunması yaşlı BESTO farelerinde glukoza duyarlı insülin sekresyonunu geri kazandırır ve glukoz toleransinı artırır (24).

Tip 2 diyabetik hastaların kas dokusunda SIRT1 protein ekspresyonunun azaldığı ve azalan SIRT1 seviyelerinin kas insülin direncinin belirlenmesinde katkısı olduğu gösterilmiştir. SIRT1, PI3K adaptör alt birimi p85 ile insülin bağımsız bir şekilde etkileşime girer ve iskelet kası hücrelerinde fizyolojik insülin konsantrasyonlarında insülin sinyalizasyonunu düzenleyebilir. Ayrıca, SIRT1 aktivatörü resveratrol, kas hücrelerini TNF- $\alpha$ veya uzun süreli hiperinsülineminin neden olduğu insülin direncinden korur. Nükleer ilişkili SIRT1, IRS-2 (insülin reseptör substrat) gibi sitoplazmik proteinlerle etkileşime girer $(25,26)$.

SIRT1 tarafindan deasetile edilen PGC-1 $\alpha$ 'nın aktivitesi artar. Artan PGC-1 $\alpha$ aktivitesi sonucunda hepatik glukoneogenez, $\beta$-yağ asidi oksidasyonu ve mitokondriyal fonksiyona katılan metabolik genlerin ekspresyonu $\operatorname{artar}(27,28)$. SIRT1, karaciğerde açlık durumunda PGC-1a ve FOXO1 aktivasyonu yoluyla glukoneogenezi teşvik eder ve hepatik glukoz çıkışını uyarır (29).
Açlık veya enerji sınırlaması sırasında karaciğer lipit kullanımını artırarak lipit ve kolesterol sentezini azaltır. SIRT1, karaciğerde PPARa ve PGC-1a'nın aktivitesini artırarak aç kalmaya cevaben mitokondriyal yağ asidi oksidasyonunu artırır (30). Fare karaciğerinde endojen SIRT1'in akut down- regülasyonunun, lipogenik genlerin ekspresyonunu arttırdığı ve $\beta$-yağ asidi oksidasyonu ve safra asidi biyosentezinde yer alan genlerin ekspresyonunu azalttığı gösterilmiștir (31). Yine farelerle yapılan başka bir çalışmada, hepatik SIRT1 delesyonunun PPAR $\alpha /$ PGC-1 1 s sinyalleşmesini zayıflatarak, yağ asidi oksidasyonu ve ketogenezde azalma, ayrıca yüksek yağlı bir diyette hepatik steatoz, iltihaplanma ve ER stresinin gelişmesine katkıda bulunduğu gösterilmiştir (32). Karaciğer X reseptörü (LXR), farnesoid X reseptörü (FXR) kolesterol ve safra asidi sensörleri olarak işlev gören önemli nükleer reseptörlerdir (33). SIRT1 ayrıca hepatik metabolik süreçleri düzenleyen bu reseptörlerin ve sterol düzenleyici element bağlayıcı proteinin (SREBP) transkripsiyonunu doğrudan modüle ederek, hepatik kolesterol ve safra asidi homeostazını düzenler. SIRT1'in SREBP aktivitesi üzerindeki etkisi nedeniyle de karaciğer yağlanması, obezite ve tip II diyabet gibi metabolik bozuklukların tedavisi için faydalı olabileceği öngörülmektedir (34).

Adipositler, aşırı doymuş lipidleri depolayabilmeleri ve adipokinleri üretebilmeleri nedeniyle, insülin direncinin ve tip 2 diyabetin gelişiminde kritik bir rol oynamaktadır. PPAR $\gamma$, yağ asidi depolanması ve glikoz metabolizmasının düzenlenmesi için temel bir moleküldür ve bu faktör adipoz doku farklılaşmasında rol oynar. Olgun beyaz yağ hücrelerinde, PPAR $\gamma$ serbest yağ asidi alımı ve trigliserid sentezinde yer

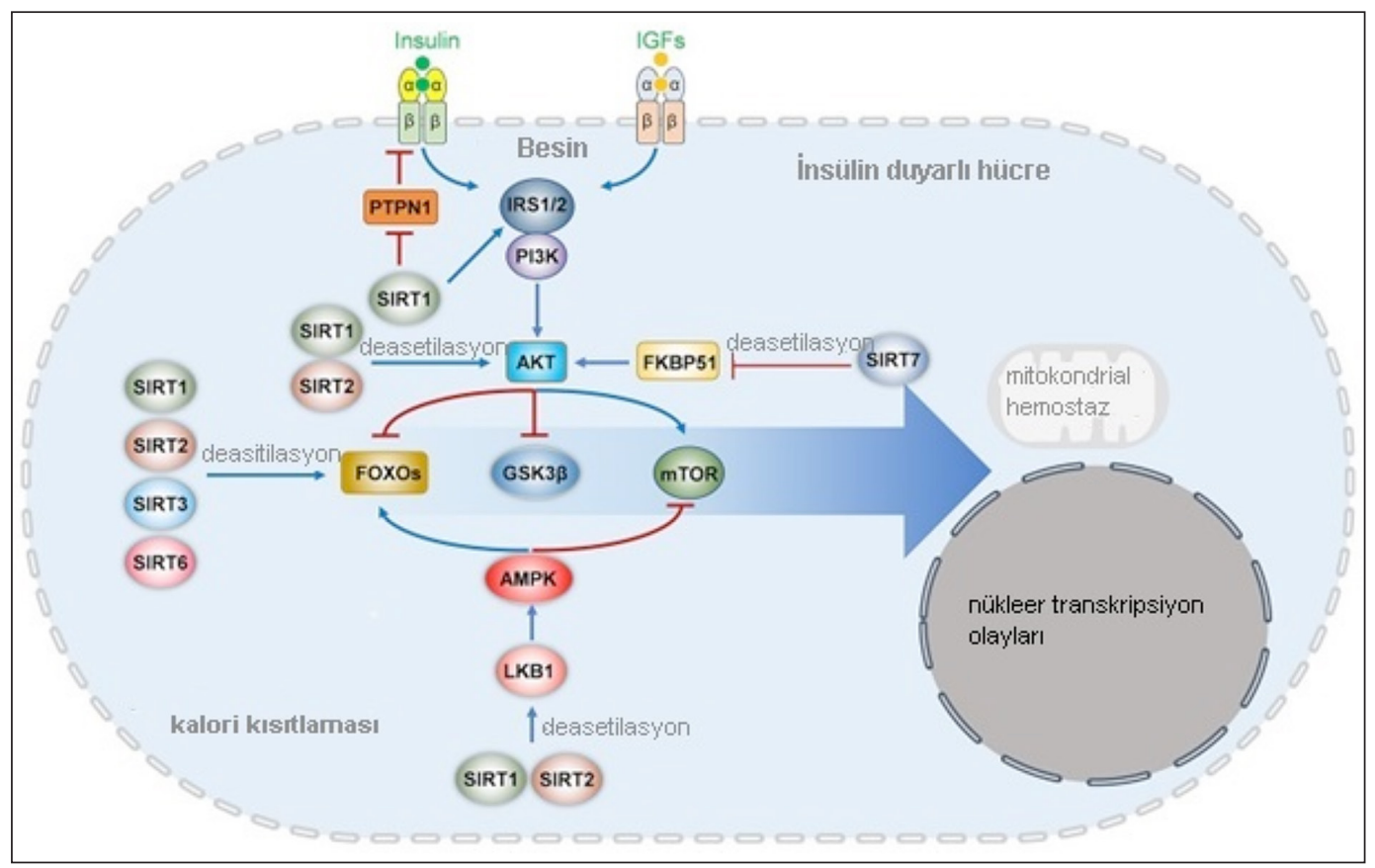

Şekil 1. Sirtuinlerin insülin sinyal yollarındaki rolü (58) 
alan genlerin indüksiyonunu düzenler, böylece hücrenin lipit depolama kapasitesini artırır. Beyaz yağ dokusunda SIRT1, PPAR $\gamma$ 'yı baskılayarak LXR'nin aktivasyonu yoluyla yağ depolanmasını azaltır, lipolizi artırarak yağ kaybını tetikler (35). Ayrıca, SIRT1'in PPAR $\gamma^{\prime} y 1$ deasetile ederek, beyaz adipoz dokunun kahverengiye dönüşümünü teşvik ettiğini göstermiştir (36).

\section{Sirtuin 2 (SIRT2)}

SIRT2 (Sirtuin 2), NAD+ bağımlı deasetilaz aktivitesine sahip, sirtuin ailesinin yedi üyesinden biridir (37). SIRT2, H3 ve $\mathrm{H} 4$ histon proteinleri, transkripsiyon faktörleri p53, p65, FOXO1 ve FOXO3A dahil olmak üzere çeşitli protein substratları ve a-tubulini deasetile eder (38). Diğer sirtuinlerin aksine, SIRT2 temel olarak sitoplazmiktir, burada a -tübülin lys40 ile kolokalize olur ve mikrotübül organizasyonunu düzenler (39). Ayrıca sitoplazmada, SIRT1'e benzer şekilde NF-кB p65 alt ünitesini deasetile ederek inflamasyon sürecinin gelişiminde koruyucu rol oynar (40). G2 / M fazı sırasında, SIRT2 çekirdeğe taşınır ve histon H4K16'yı deasetile eder, böylece metafaz sırasında kromatin yoğunlaşmasını modüle eder. SIRT2 seviyeleri mitozda artar ve aşırı ekspresyonu M fazını uzatarak mitotik çıkışı geciktirir (41).

Yapılan çalışmalarda, SIRT2'nin, inflamasyon ve mitotik fonksiyonunun yanı sıra oksidatif stres, adiposit farklılaşması, yağ asidi oksidasyonu, glukoneogenez ve insülin duyarlılı̆̆ dahil olmak üzere metabolik homeostazın korunmasında çeşitli fizyolojik süreçlerde önemli bir rol oynadığ 1 gösterilmiştir (42).

SIRT2, adiposit dokularda en bol bulunan memeli sirtuinidir ve burada FOXO1'i deasetile ederek adiposit farkl1laşmasını negatif düzenler. FOXO1 deasetile olduğunda PPAR $\gamma^{\prime} y a$ bağlanması artar, bu da PPAR $\gamma$ aktivitesinin ve dolayısıyla adiposit farklılaşmasının baskılanmasına neden olur (43). Yapilan çalışmalarda da, SIRT2 ekspresyonunun lipolizi desteklediği ve adiposit farklılaşmasını önleyerek enerji homeostazını korumak için besin yoksunluğuna ve enerji harcamalarına cevap verdiği gösterilmiştir. $\mathrm{Bu}$ nedenle, SIRT2 aktivitesini modüle etmenin, obezitedeki artan yağ kütlesinden kaynaklanan metabolik bozuklukları kısmen iyileştirebileceği tahmin edilmektedir $(43,44)$.

Fizyolojik glikoz seviyesi düşük olduğunda beyin veya diğer önemli organlara glukoz sağlamak için hızlı bir şekilde glukoneogenezin artırılması gerekir. Bu durum glikoneogenezdeki hız sinırlayıcı enzim olan hücresel Fosfoenolpirüvat Karboksikinaz 1 (PEPCK1) aktivitesinde hızlı bir değişiklik yapılmasını gerektirir. Glukoz seviyesi düşük olduğunda, PEPCK1 stabilize edilir ve glukoneogenez arttırılır. SIRT2'nin, PEPCK1'in deasetillenmesi ve stabilize edilmesinde etkili olarak glukoz homeostazının korunmasında önemli bir rol oynar (45).
SIRT2 inhibitörü sirtinol uygulaması ile yapılan bir çalışmada, SIRT2 aktivitesinin inhibisyonunun karaciğer PEPCK1 protein seviyesinde ve glikoneogenezde azalmaya neden olduğu, ayrıca piruvatın neden olduğu kan glukozunun yükselmesini önlediği gösterilmiştir. PEPCK1 tip 2 diyabetin değerlendirilmesinde önemli bir belirteçtir (46).

Ayrıca SIRT2'nin hepatik glukoz alımında rol oynadığ bildirilmiştir. Bozulan hepatik glukoz alımı, tip 2 diyabetle ilişkili postprandiyal hiperglisemi ile sonuçlanır ve daha yüksek glikoz seviyelerine neden olabilir. Hepatik glukoz alımı, glukokinaz ve glukoz-6-fosfataz ile düzenlenir. Obez diyabetik farelerde hepatik glukoz alımı bozukluğunun kısmen hepatik NAD + bağımlı SIRT2 aktivitesinde bir azalmaya neden olduğu ve glukokinaz düzenleyici protein (GKRP) K126'nın SIRT2'ye bağlı deasetilasyonunda bir kusurdan kaynaklandığ 1 gösterilmiştir. Diyabetik olmayan farelerin karaciğerinde SIRT2'nin yokluğu, glikoz intoleransına neden olur. Diyabetik farelerde SIRT2 over ekspresyonu ise, glukoz toleransını artırır ve GKRP K126'nın deasetilasyonu ile hepatik glukoz alımını artırır (47).

\section{SIRT1/SIRT2 GEN POLIMORFIZMLERİ VE DIAABTES MELLITUS}

SIRT1 genindeki birçok polimorfizm ile tip2 diyabet arasındaki ilişki farklı etnik gruplarda çalışılmış olup elde edilen veriler çelişkilidir (Tablo 1). Bazı çalışmalarda rs10823112, rs4746720, rs10509291, rs7896005 ve rs 10823116 polimorfizmleri ile tip 2 diyabet arasında ilişki olduğu gösterilirken bazı çalışmalarda bu polimorfizmlerin ilişkili olmadığı belirlenmiştir (48-56). Zhuanping ve ark. tarafından rs4746720 $\mathrm{CC}+\mathrm{TT}$ genotiplerinin sağlıksız beslenen bireylerde tip2 diyabet riskini artırdığı gösterilirken (51) Japon popülasyonunda da rs2236319, rs10823108, rs3818292 ve rs4746720 polimorfizmlerinin diyabetik nefropati riskini artırdığı gösterilmiştir. Bu sonuçlara dayanarak da SIRT1'in diyabetik nefropati gelişiminde rolü olduğu öne sürülmüştür (52). Ancak SIRT2 gen polimorfizmi ile diyabet arasındaki ilişkiyi araştıran çok az çalışma bulunmakta ve bu çalışmalarda SIRT2 gen polimorfizmi ile diyabet arasinda herhangi bir ilişki bulunamamıştır $(54,57)$.

\section{SONUÇ}

SIRT1 ve SIRT2'nin hücre döngüsünün düzenlenmesi, yaşlanma, hücresel stres yanıtı, apoptozis, sirkadiyen ritim, mitokondriyal biyogenez, inflamasyon gibi çeşitli fizyolojik süreçlerde etkin olmasının yanı sıra; adiposit farklılaşması, yağ asidi oksidasyonu, glukoneogenez ve insülin duyarlılığı dâhil olmak üzere glukoz homeostazında etkili süreçlerde önemli rol oynadığı gösterilmiştir. Bu moleküllerle ilişkili genetik ve epigenetik değişikliklerin diyabetle ilişkisini araştıran çalışmalar yapılmakta ve çarpıcı sonuçlar alınmaktadir. Bu nedenle SIRT1 ve SIRT2 tip 2 diyabet tedavisinde yeni moleküler hedefler olabilir ve bu konuda yapılacak çalışmalar diyabet tedavisine yeni bir boyut kazandırabilir. 
Tablo 1: SIRT1/SIRT2 gen polimorfizmleri ile Diyabet arasındaki ilişkiyi inceleyen çalışmalar

\begin{tabular}{|c|c|c|}
\hline Gen & Polimorfizm ve Diyabet ile ilişkisi & Referans \\
\hline \multirow[t]{9}{*}{ SIRT1 } & $\begin{array}{l}\text { rs10823112+ } \\
\text { rs4746720 + } \\
\text { rs10509291+ }\end{array}$ & Han J et al. (48) \\
\hline & rs12778366 - & Gambino R et al. (49) \\
\hline & $\begin{array}{l}\text { rs3758391 - } \\
\text { rs12778366 - }\end{array}$ & Peng Y et al. (50) \\
\hline & $\begin{array}{l}\text { rs4746720 + } \\
\text { rs10509291 - } \\
\text { rs2236319 - } \\
\text { rs10823116 + }\end{array}$ & Zhuanping $\mathrm{Z}$ et al. (51) \\
\hline & $\begin{array}{l}\text { rs381829 - } \\
\text { rs4746720 - } \\
\text { rs10823108+ }\end{array}$ & Zhao Y et al. (52) \\
\hline & rs7896005+ & Domínguez-Cruz MG et al. (53) \\
\hline & $\begin{array}{l}\text { rs12778366 - } \\
\text { rs3740051 - } \\
\text { rs2236318 - } \\
\text { rs2236319+ } \\
\text { rs10823108+ } \\
\text { rs10997868 - } \\
\text { rs2273773 - } \\
\text { rs3818292+ } \\
\text { rs3818291 - } \\
\text { rs4746720+ } \\
\text { rs10823116 - }\end{array}$ & Maeda S et al. (54) \\
\hline & $\begin{array}{l}\text { rs12778366- } \\
\text { rs3758391- } \\
\text { rs7476338- } \\
\text { rs35706870- } \\
\text { rs3740051- } \\
\text { rs34639502- } \\
\text { rs34842975- } \\
\text { rs932658- } \\
\text { rs35995735- } \\
\text { rs3740053- } \\
\text { rs2394443- } \\
\end{array}$ & Rai E et al. (55) \\
\hline & $\begin{array}{l}\text { rs7895833- } \\
\text { rs10509291 + } \\
\text { rs7896005 + } \\
\text { rs4746720- }\end{array}$ & Dong Y et al. (56) \\
\hline \multirow[t]{2}{*}{ SIRT2 } & $\begin{array}{l}\text { rs10713585 - } \\
\text { rs4803006 - } \\
\text { rs116900177 - } \\
\text { rs2053071 - } \\
\text { rs112492606 - }\end{array}$ & Liu T et al. (57) \\
\hline & $\begin{array}{l}\text { rs1001413- } \\
\text { rs892034- } \\
\text { rs2015- } \\
\text { rs2241703- } \\
\text { rs2082435- rs11575003- } \\
\text { rs2053071- }\end{array}$ & Maeda S et al. (54) \\
\hline
\end{tabular}

\footnotetext{
“+” ilişkili olduğu tespit edilmiştir. “_” ilişkili olmadığı tespit edilmiştir.
} 
Teșekkür

Yok.

Yazarların Makaleye Katkı Beyanı

Makale tasarımı: Sevim Karakaş Çelik, Güneş Genç Çakmak ve İlke Ulu, Literatür taraması: Güneş Genç Çakmak ve İlke Ulu, Makale yazımı: Sevim Karakaș Çelik, Güneș Genç Çakmak ve İlke Ulu ve Dergi yazım kurallarına uygun şekilde düzenlenerek gönderilmesi: Sevim Karakaş Çelik tarafından yapılmıştır.

\section{Çıkar Çatışması}

Yazarların beyan edecek herhangi bir çıkar çatışmaları yoktur.

Finansal Destek

Bu çalışmanın yapılabilmesi için herhangi bir finansal destek alınmamıştır.

\section{Etik Kurul Onayı}

Deneysel veya insan ile ilgili bir araştırma olmadığından etik kurul oluru gerekmemiştir.

\section{Hakem Değerlendirmesi}

Kör hakemlik süreci sonrası yayınlanmaya uygun bulunmuş ve kabul edilmiştir.

\section{KAYNAKLAR}

1. Saltiel AR, Kahn CR. Insulin signalling and the regulation of glucose and lipid metabolism. Nature. 2001;414(6865):799806.

2. Satman I, Omer B, Tutuncu Y, Kalaca S, Gedik S, Dinccag N ve ark. Twelve-year trends in the prevalence and risk factors of diabetes and prediabetes in Turkish adults. Eur J Epidemiol. 2013;(28):169-180.

3. Whiting DR, Guariguata L, Weil C, Shaw J. IDF Diabetes Atlas: Global estimates of the prevalence of diabetes for 2011 and 2030. Diabetes Res Clin Pract. 2011;94(3): 311-321.

4. Cho NH, Shaw JE, Karuranga S, Huang Y, da Rocha Fernandes JD, Ohlrogge AW, Malanda B. IDF Diabetes Atlas: Global estimates of diabetes prevalence for 2017 and projections for 2045. Diabetes Res Clin Pract. 2018;(138):271-281.

5. International Diabetes Federation. IDF Diabetes Atlas, 8th edn. Brussels, Belgium: International Diabetes Federation, 2017. http://www.diabetesatlas.org. Erişim Tarihi: 10 Nisan 2018.

6. American Diabetes Association. 1. Improving care and promoting health in populations: Standards of Medical Care in Diabetes-2019. Diabetes Care. 2019;42(1):7-12.

7. Gan SK, Kriketos AD, Ellis BA, Thompson CH, Kraegen EW, Chisholm DJ. Changes in aerobic capacity and visceral fat but not myocyte lipid levels predict increased insulin action after exercise in overweight and obese men. Diabetes Care. 2003;26(6):1706-1713.
8. Williams KV, Kelley DE. Metabolic consequences of weight loss on glucose metabolism and insulin action in type 2 diabetes. Diabetes Obes Metab. 2000;(2):121-129.

9. Poulose N, Raju R. Sirtuin regulation in aging and injury. Biochim Biophys Acta. 2015;1852(11):2442-2455.

10. Michan S, Sinclair D. Sirtuins in mammals: Insights into their biological function. Biochem J. 2007;404(1):1-13.

11. Flick F, Lüscher B. Regulation of sirtuin function by posttranslational modifications. Front Pharmacol. 2012;3:29.

12. Roth M, Chen WY. Sorting out functions of sirtuins in cancer. Oncogene. 2014;33(13):1609-1620.

13. Chang HC, Guarente L. SIRT1 and other sirtuins in metabolism. Trends Endocrinol Metab. 2014;25(3):138-145.

14. Taddei A, Roche D, Bickmore WA, Almouzni G. The effects of histone deacetylase inhibitors on heterochromatin: Implications for anticancer therapy? EMBO Rep. 2005;6(6):520-524.

15. Palmirotta R, Cives M, Della-Morte D, et al. Sirtuins and cancer: Role in the epithelial-mesenchymal transition. Oxid Med Cell Longev. 2016;2016:3031459.

16. Roth M, Chen WY. Sorting out functions of sirtuins in cancer. Oncogene. 2014; 33(13): 1609-1620.

17. Vaquero A, Scher M, Lee D, Erdjument-Bromage H, Tempst P, Reinberg D. Human SirT1 interacts with histone H1 and promotes formation of facultative heterochromatin. Mol Cell. 2004;16(1): 93-105.

18. Kitada M, Koya D. SIRT1 in type 2 diabetes: Mechanisms and therapeutic potential. Diabetes Metab J. 2013;37(5):315-325.

19. Liu T, Liu PY, Marshall GM. The critical role of the class III histone deacetylase SIRT1 in cancer. Cancer Res. 2009;69(5): 1702-1705.

20. Bordone L, Guarente L. Calorie restriction, SIRT1 and metabolism: Understanding longevity. Nat Rev Mol Cell Biol. 2005;6:298-305.

21. Bordone L, Motta M C, Picard F, Robinson A, Jhala US, Apfeld J, McDonagh T, Lemieux M, McBurney M, Szilvasi A, Easlon EJ, Lin SJ, Guarente L. Sirt1 regulates insulin secretion by repressing UCP2 in pancreatic beta cells. PLoS Biol. 2006;4(2): e31.

22. Lee JH, Song MY, Song EK, Kim EK, Moon WS, Han MK, Park JW, Kwon KB, Park BH. Overexpression of SIRT1 protects pancreatic beta-cells against cytokine toxicity by suppressing the nuclear factor-kappaB signaling pathway. Diabetes. 2009;58:344-351.

23. Moynihan KA, Grimm AA, Plueger MM, Bernal-Mizrachi E, Ford E, Cras-Meneur C, Permutt MA, Imai S. Increased dosage of mammalian Sir2 in pancreatic beta cells enhances glucose-stimulated insulin secretion in mice. Cell Metab 2005;2:105-117.

24. Ramsey KM, Mills KF, Satoh A, Imai S. Age-associated loss of Sirt1-mediated enhancement of glucose-stimulated insulin secretion in beta cell-specific Sirt1-overexpressing (BESTO) mice. Aging Cell. 2008;7:78-88. 
25. Frojdo S, Durand C, Molin L, Carey AL, El-Osta A, Kingwell BA, Febbraio MA, Solari F, Vidal H, Pirola L. Phosphoinositide 3-kinase as a novel functional target for the regulation of the insulin signaling pathway by SIRT1. Mol Cell Endocrinol. 2011;335:166-176.

26. Zhang J. The direct involvement of SirT1 in insulin-induced insulin receptor substrate- 2 tyrosine phosphorylation. J Biol Chem. 2007;282:34356-34364.

27. Rodgers JT, Lerin C, Gerhart-Hines Z, Puigserver P. Metabolic adaptations through the PGC-1 alpha and SIRT1 pathways. FEBS Lett. 2008; 582(1):46-53.

28. Puigserver P, Spiegelman BM. Peroxisome proliferatoractivated receptor-gamma coactivator 1 alpha (PGC-1 alpha): Transcriptional coactivator and metabolic regulator. Endocr Rev. 2003; 24(1):78-90.

29. Rodgers JT, Lerin C, Haas W, Gygi SP, Spiegelman BM, Puigserver P. Nutrient control of glucose homeostasis through a complex of PGC-1alpha and SIRT1. Nature. 2005; 434(7029):113-118.

30. Kitada M, Koya D. SIRT1 in Type 2 diabetes: Mechanisms and therapeutic potential. Diabetes Metab J. 2013;37(5):315-325.

31. Rodgers JT, Puigserver P. Fasting-dependent glucose and lipid metabolic response through hepatic sirtuin 1. Proc Natl Acad Sci U S A. 2007; 104(31):12861-12866.

32. Purushotham A, Schug TT, Xu Q, Surapureddi S, Guo X, Li X. Hepatocyte-specific deletion of SIRT1 alters fatty acid metabolism and results in hepatic steatosis and inflammation. Cell Metab. 2009; 9(4):327-338.

33. Mangelsdorf DJ, Evans RM. The RXR heterodimers and orphan receptors. Cell. 1995; 83(6):841-850.

34. Ponugoti B, Kim DH, Xiao Z, Smith Z, Miao J, Zang M, Wu SY, Chiang CM, Veenstra TD, Kemper JK. SIRT1 deacetylates and inhibits SREBP-1C activity in regulation of hepatic lipid metabolism. J Biol Chem. 2010;285(44):33959-339570.

35. Picard F, Kurtev M, Chung N, Topark-Ngarm A, Senawong T, Machado De Oliveira R, Leid M, McBurney MW, Guarente L. Sirt1 promotes fat mobilization in white adipocytes by repressing PPAR-gamma. Nature. 2004;429:771-776.

36. Qiang L, Wang L, Kon N, Zhao W, Lee S, Zhang Y, Rosenbaum M, Zhao Y, Gu W, Farmer SR, Accili D. Brown remodeling of white adipose tissue by SirT1-dependent deacetylation of Ppary. Cell. 2012;150:620-632.

37. Smith JS, Brachmann CB, Celic I, Kenna MA, Muhammad S, Starai VJ, Avalos JL, Escalante-Semerena JC, Grubmeyer C, Wolberger C, Boeke JD. A phylogenetically conserved NADdependent protein deacetylase activity in the Sir2 protein family. Proc Natl Acad Sci USA. 2000;97:6658-6663.

38. De Oliveira RM, Sarkander J, Kazantsev AG, Outeiro TF. SIRT2 as a therapeutic target for age-related disorders. Front Pharmacol, 2012; 3: 82.

39. North BJ, Marshall BL, Borra MT, Denu JM, Verdin E. The human Sir2 ortholog, SIRT2, is an NAD+-dependent tubulin deacetylase. Mol Cell. 2003; 11(2): 437-444.
40. Rothgiesser KM, Erener S, Waibel S, Lüscher B, Hottiger MO. SIRT2 regulates NF- $\kappa \mathrm{B}$ dependent gene expression through deacetylation of p65 Lys310. J Cell Sci. 2010; 123(Pt 24): 42514258.

41. Vaquero A, Scher MB, Lee DH, Sutton A, Cheng HL, Alt FW, Serrano L, Sternglanz R, Reinberg D. SirT2 is a histone deacetylase with preference for histone H4 Lys 16 during mitosis. Genes Dev. 2006; 20(10): 1256-1261.

42. Gomes P, Fleming Outeiro T, Cavadas C. Emerging role of Sirtuin 2 in the regulation of mammalian metabolism. Trends Pharmacol Sc. 2015;36:756-768.

43. Jing E, Gesta S, Kahn CR. SIRT2 regulates adipocyte differentiation through FoxO1 acetylation/deacetylation. Cell Metab. 2007; 6(2): 105-114.

44. Wang F, Tong Q. SIRT2 suppresses adipocyte differentiation by deacetylating FOXO1 and enhancing FOXO1's repressive interaction with PPARgamma. Mol Biol Cell.2009;20:801-808.

45. Jiang W, Wang S, Xiao M, Lin Y, Zhou L, Lei Q, Xiong Y, Guan KL, Zhao S. Acetylation regulates gluconeogenesis by promoting PEPCK1 degradation via recruiting the UBR5 ubiquitin ligase. Mol Cell. 2011; 43(1): 33-44.

46. Zhang M, Pan Y, Dorfman RG, Yin Y, Zhou Q, Huang S, Liu J, Zhao S. Sirtinol promotes PEPCK1 degradation and inhibits gluconeogenesis by inhibiting deacetylase SIRT2. Sci Rep. 2017;7(1):7.

47. Watanabe H, Inaba Y, Kimura K, Matsumoto M, Kaneko S, Kasuga M, Inoue $\mathrm{H}$. Sirt2 facilitates hepatic glucose uptake by deacetylating glucokinase regulatory protein. Nat Commun. 2018; 9(1):30.

48. Han J, Wei M, Wang Q, Li X, Zhu C, Mao Y, Wei L, Sun Y, Jia W. Association of genetic variants of SIRT1 with type 2 diabetes mellitus. Gene Expr. 2015;16(4):177-185.

49. Gambino R, Fanni G, Togliatto G, Ponzo V, Goitre I, Cassader M, Brizzi MF, Bo S. Rs12778366 single nucleotide polymorphism of Sirtuin 1 (SIRT1) and response to resveratrol supplementation in patients with type 2 diabetes mellitus. Acta Diabetol. 2019;56(8):963-966.

50. Peng Y, Zhang G, Tang H, Dong L, Gao C, Yang X, Peng $\mathrm{Y}, \mathrm{Xu}$ Y. Influence of SIRT1 polymorphisms for diabetic foot susceptibility and severity. Medicine (Baltimore). 2018;97(28):e11455.

51. Zhuanping Z, Rifang L, Qing C, Sidong C. The Association between SIRT1 genetic variation and type 2 diabetes mellitus is influenced by dietary intake in elderly Chinese. Iran J Public Health. 2018;47(9):1272-1280.

52. Zhao Y, Wei J, Hou X, Liu H, Guo F, Zhou Y, Zhang Y, Qu Y, Gu J, Zhou Y, Jia X, Qin G, Feng L. SIRT1 rs10823108 and FOXO1 rs17446614 responsible for genetic susceptibility to diabetic nephropathy. Sci Rep. 2017;7(1):10285.

53. Domínguez-Cruz MG, Muñoz ML, Totomoch-Serra A, García-Escalante MG, Burgueño J, Valadez-González N, Pinto-Escalante D, Díaz-Badillo A. Maya gene variants related to the risk of type 2 diabetes in a family-based association study. Gene. 2020;730:144259. 
54. Maeda S, Koya D, Araki SI, Babazono T, Umezono T, Toyoda M, Kawai K, Imanishi M, Uzu T, Suzuki D, Maegawa H, Kashiwagi A, Iwamoto Y, Nakamura Y. Association between single nucleotide polymorphisms within genes encoding sirtuin families and diabetic nephropathy in Japanese subjects with type 2 diabetes. Clin Exp Nephrol. 2011;15(3):381-390.

55. Rai E, Sharma S, Kaul S, Jain K, Matharoo K, Bhanwer AS, Bamezai RN. The interactive effect of SIRT1 promoter region polymorphism on type 2 diabetes susceptibility in the North Indian population. PLoS One. 2012;7(11):e48621.
56. Dong Y, Guo T, Traurig M, Mason CC, Kobes S, Perez J, Knowler WC, Bogardus C, Hanson RL, Baier LJ. SIRT1 is associated with a decrease in acute insulin secretion and a sex specific increase in risk for type 2 diabetes in Pima Indians. Mol Genet Metab. 2011;104(4):661-665.

57. Liu T, Yang W, Pang S, Yu S, Yan B. Functional genetic variants within the SIRT2 gene promoter in type 2 diabetes mellitus. Diabetes Res Clin Pract. 2018;137:200-207.

58. Zhou S, Tang X, Chen HZ. Sirtuins and Insulin Resistance. Front Endocrinol (Lausanne). 2018;9:748. 